\title{
Solventless Sol-Gel Chemistry Through Ring-Opening Polymerization of Bridged \\ Disilaoxacyclopentanes
}

Kamyar Rahimian* ${ }^{1}$, Douglas A. Loy $*^{2}$

${ }^{1}$ Organic materials Department, Sandia National Laboratories, Albuquerque, NM 87185-140

${ }^{2}$ Catalysis and Chemical Technologies Department, Sandia National Laboratories, Albuquerqud,

NM 87185-1407

\section{INRTODUCTION}

Ring-opening polymerization (ROP) of disilaoxacyclopentanes has proven to be an excellent approach to sol-gel type hybrid orgainc-inorganic materials [1]. These materials have shown promise as precursors for encapsulation and microelectronics applications (Figure 1). The polymers are highly crosslinked and are structurally similar to traditional sol-gels, but unlike typical sol-gels they are prepared by an organic base or Bronsted acid (formic or triflic acid), without the use of solvents and water, they have low VOC's and show little shrinkage during processing.

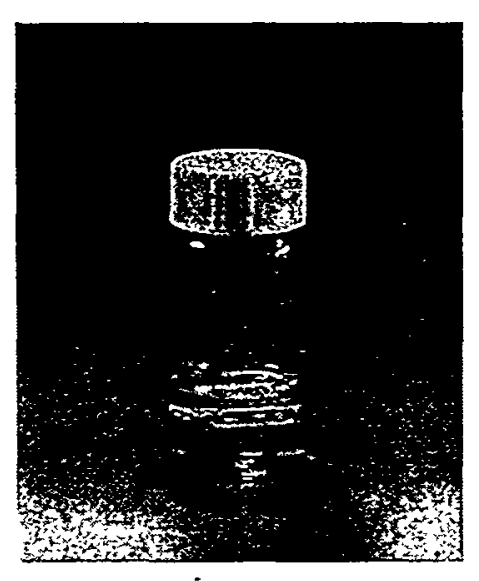

Figure 1. Microelectronic test chip encapsulated with a mixture of $2 / 1$.

The first representatives of this new clas of hybrid materials were prepared from the ROP of the phenlene-bridged disilaoxacyclopentane monomer 1 (Scheme 1). However, because pure monomer 1 is a solid, solvent-free polymerization must be performed either in the melt or in the presence of 2 , as a copolymer system. It would be advantageous to have liquid monomers which would behave in the same manner as 1 . By replacing the rigid phenylene group with more flexible alkylene bridging groups, it is possible to have monomers which can be directly used for solvent free polymerization at room temperature. 


\section{DISCLAIMER}

This report was prepared as an account of work sponsored by an agency of the United States Government. Neither the United States Government nor any agency thereof, nor any of their employees, make any warranty, express or implied, or assumes any legal liability or responsibility for the accuracy, completeness, or usefulness of any information, apparatus, product, or process disclosed, or represents that its use would not infringe privately owned rights. Reference herein to any specific commercial product, process, or service by trade name, trademark, manufacturer, or otherwise does not necessarily constitute or imply its endorsement, recommendation, or favoring by the United States Government or any agency thereof. The views and opinions of authors expressed herein do not necessarily state or reflect those of the United States Government or any agency thereof. 


\section{DISCLAIMER}

Portions of this document may be illegible in electronic image products. Images are produced from the best available original document. 
Scheme 1. Homo-polymerization of 1 and its copolymerization with 2.
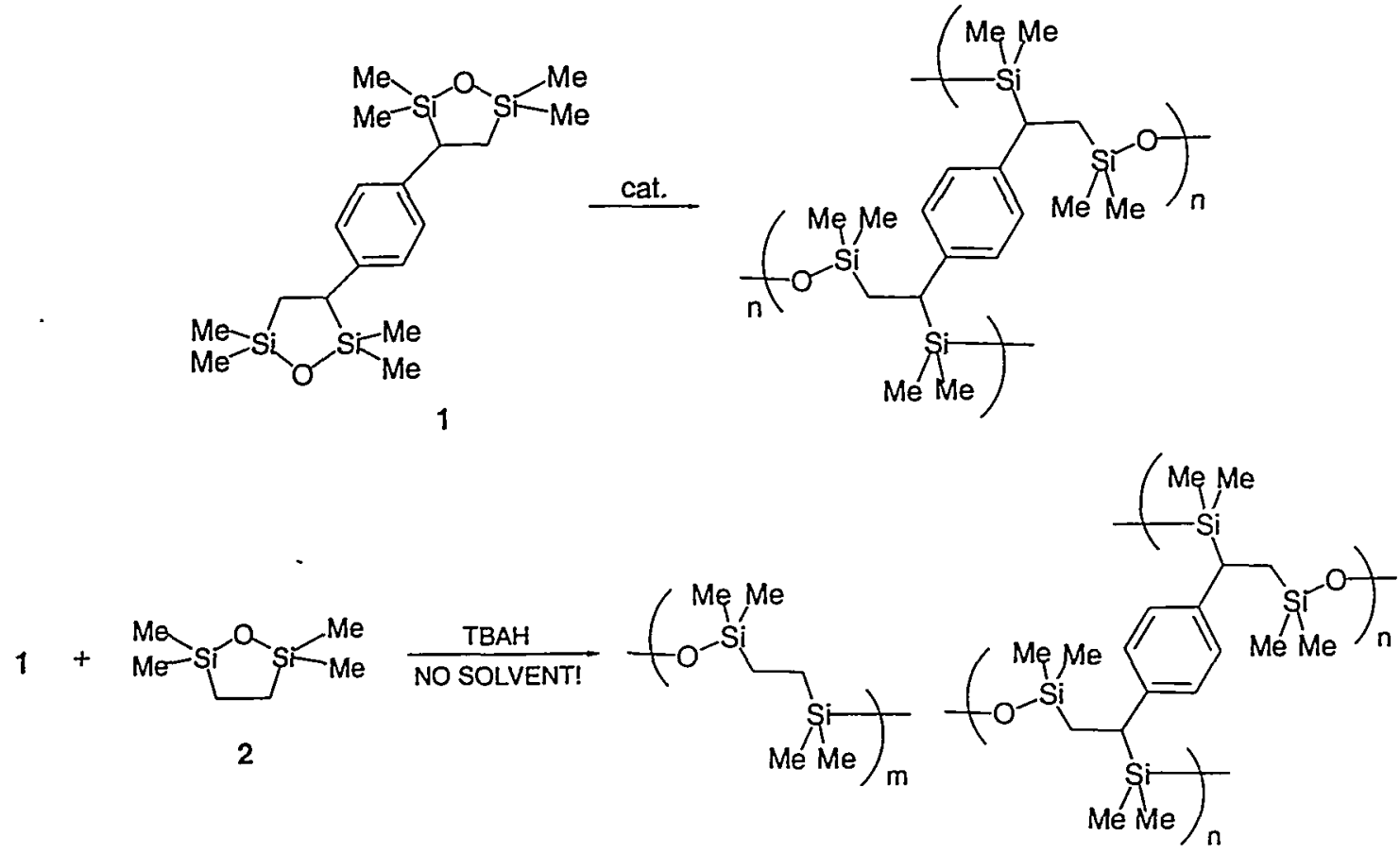

The following report discusses the synthesis of alkylene-bridged disilaoxacyclopentanes, which are liquid monomers, as well as the ring-opening polymerization of disilaoxacyclopentanes using acids and photo-generated acids (PAG) and their use in thin films and coatings applications.

\section{EXPERIMENTAL SECTION}

The ethylene- and butylene-bridged disilaoxacyclopentanes are synthesized by the same methodology as the previously reported phenylene-bridged disilaoxacyclopentane, 1 (scheme $2)$, 'with one difference. The hydrogenation step is performed under higher pressure ( $-800 \mathrm{psi})$, and in the presence of formic acid as a hydrogenation accelerator.

\section{RESULTS AND DISCUSSION}

Synthesis of Base-Catalyzed ROP of Alkylene-Bridged Disilaoxacyclopentanes. The alkylene-bridged disilaoxacyclopentanes $\left(3, \mathrm{R}=1,2-\mathrm{Et} ; 4, \mathrm{R}=1,4-\mathrm{Bu}^{\mathrm{n}}\right)$ are synthesized according to Scheme 2. This is the same methodology that was utilized for the synthesis of phenylene-bridged disilaoxacyclopentane [1] with one difference. The hydrogenation of the disilaoxacyclopentenes requires higher $\mathrm{H}_{2}$ pressure $(-800 \mathrm{psi})$ and the presence of formic acid as hydrogenation accelerator [2]. Monomers 3 and 4 are high boiling, colorless liquids/oils that display the same spectroscopic characteristics as 1 , in the cyclosiloxane region of the monomers. 
Scheme 2.
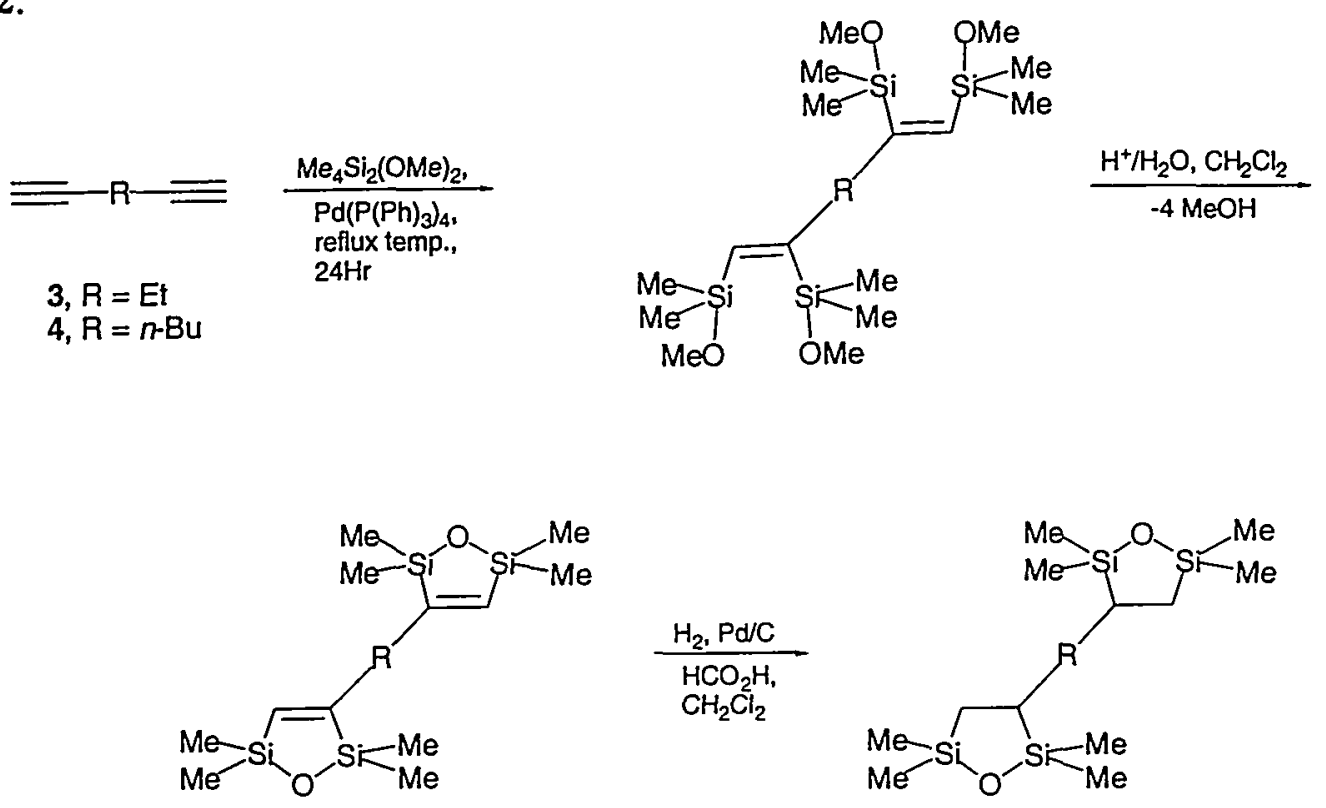

The polymerizations can be performed either neat or with 2 as a comonomer, using TBAH. Unlike monomer 1 which requires elevated temperatures for homopolymerization, monomers 3 and 4, both liquids, can be homopolymerized at room temperature. The polymerizations for the alkylene-bridged disilaoxacyclopentanes are slower than those of the phenylene-bridged monomer 1. Furthermore, their ROP with 2 are not exothermic as was observed with that of 1 . Polymers of 3 and 4 produce transparent materials which do not display any visible shrinkage.

The homopolymers of 3 and 4 have $T_{g}$ of $-23^{\circ} \mathrm{C}$ and $-33.5^{\circ} \mathrm{C}$, respectively, whereas homopolymer of 1 has a much higher $\mathrm{T}_{\mathrm{g}}$ of $80^{\circ} \mathrm{C}$ (Table 1). This trend is expected: as more flexibility is introduced into the material (alkylene bridges), the $T_{g}$ is lowered. At the same time, the coeffiecient of thermal expansion (CTE) increases. These property trends also hold for the copolymer systems of 3 and 4.

Table 1. Effect of bridging group on thermal properties of gels.

\begin{tabular}{|c|c|c|}
\hline Bridging Group & $\mathbf{T}_{\mathbf{g}}\left({ }^{\circ} \mathrm{C}\right)$ & $\mathbf{C T E}\left(\mathrm{e}^{-6 /} /{ }^{\circ} \mathrm{C}\right)$ \\
\hline Phenylene & 80 & 110 \\
\hline Ethylene & -23 & 274 \\
\hline$n$-Butylene & -33.5 & 227 \\
\hline
\end{tabular}

Similar trends are also observed when comparing the thermal properties of final materials within the same family of bridging group. For example, when the linear co-monomer is used with the phenylene-bridged disilaoxacyclopentane 1 , the $T_{g}$ of the final material decreases dramatically to approximately $-80^{\circ} \mathrm{C}$. Increasing the amount of 2 lowers the $T_{g}$ and increases the CTE of the final material (Table 2). However, since 1 is a solid precursor, it has a solubility limit of about $20 \%$ (by weight) in 2 .

Solubility is not a limiting factor when using the alkylene-bridged precursors since they are liquids. One can easily vary the amount of the bridging component in the mixture from minor to major component of the final materials (Table 2). For example, one can vary the amount of the 
bridging component 4 from $25 \%$ to $75 \%$ (by weight) in the final material. A plot of the crosslinking component versus the $\mathrm{T}_{\mathfrak{g}}$ or CTE has a linear relationship (Plots 1,2 ). Thus one can easily choose the appropriate amount of the crosslinking component for a specific application by referring to the plot.

Table 2. Effect of linear co-monomer on thermal properties of gels.

\begin{tabular}{|c|c|c|}
\hline $\begin{array}{c}\text { Copolymer mix ratio } \\
\text { (by weight, bridge:linear) }\end{array}$ & $\mathrm{T}_{\mathbf{g}}\left({ }^{\circ} \mathrm{C}\right)$ & $\mathbf{C T E}\left(\mathrm{e}^{-6} /{ }^{\circ} \mathrm{C}\right)$ \\
\hline Phenylene bridged, $1: 9$ & -81 & 352 \\
\hline Phenylene bridged, $1: 4$ & -74 & 302 \\
\hline Ethylene bridged, $1: 4$ & -75 & 335 \\
\hline$n$-Butylene bridged, $1: 3$ & $\sim-82$ & 268 \\
\hline$n$-Butylene bridged, $1: 1$ & -69 & 244 \\
\hline$n$-Butylene bridged, $3: 1$ & -53 & 236 \\
\hline
\end{tabular}

Plot 1. Plot of the amount of 4 versus $\mathrm{T}_{\mathrm{g}}$.

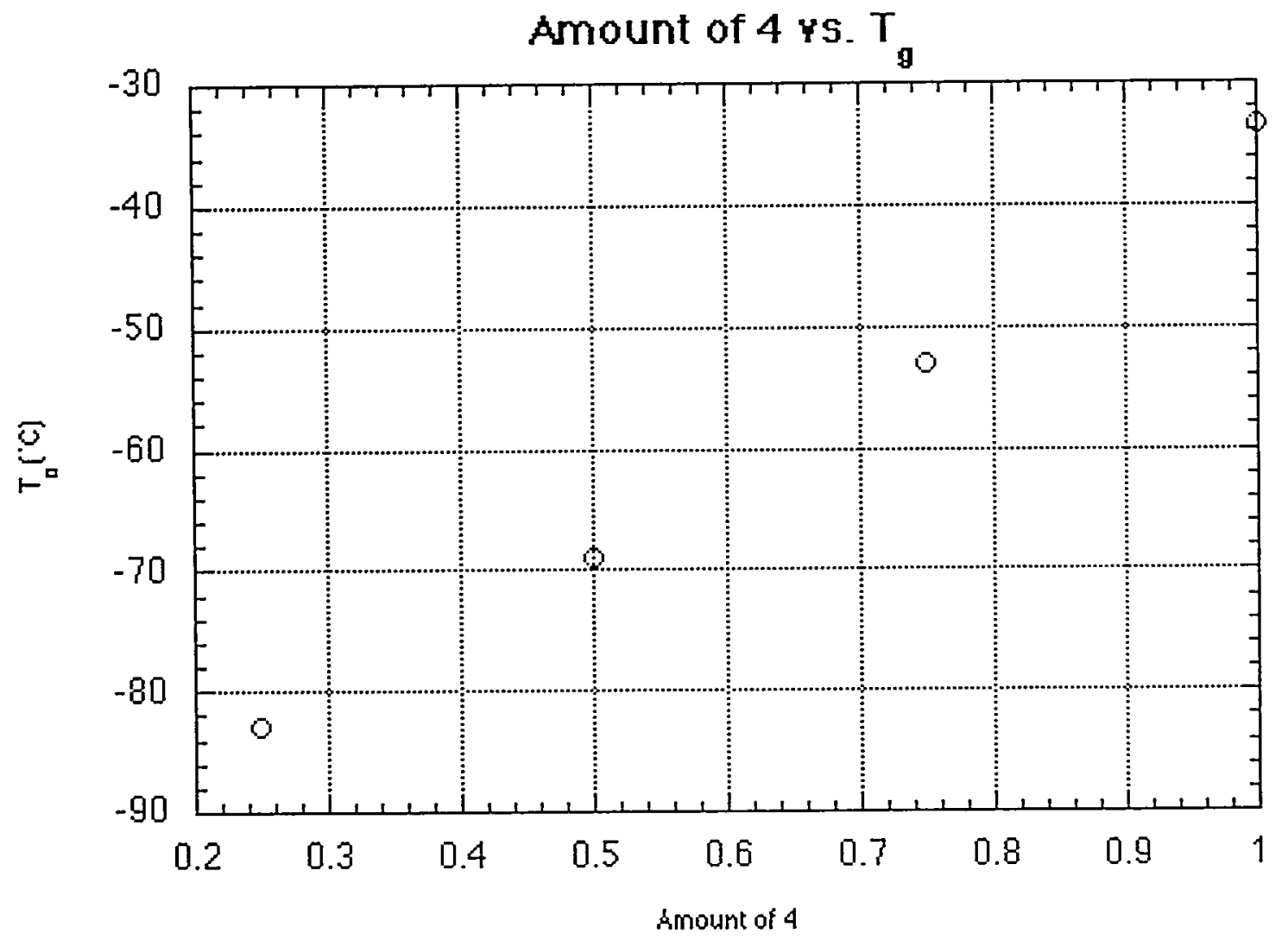


Plot 2. Plot of the amount of 4 versus CTE.

Amount of 4 ҮS. CTE

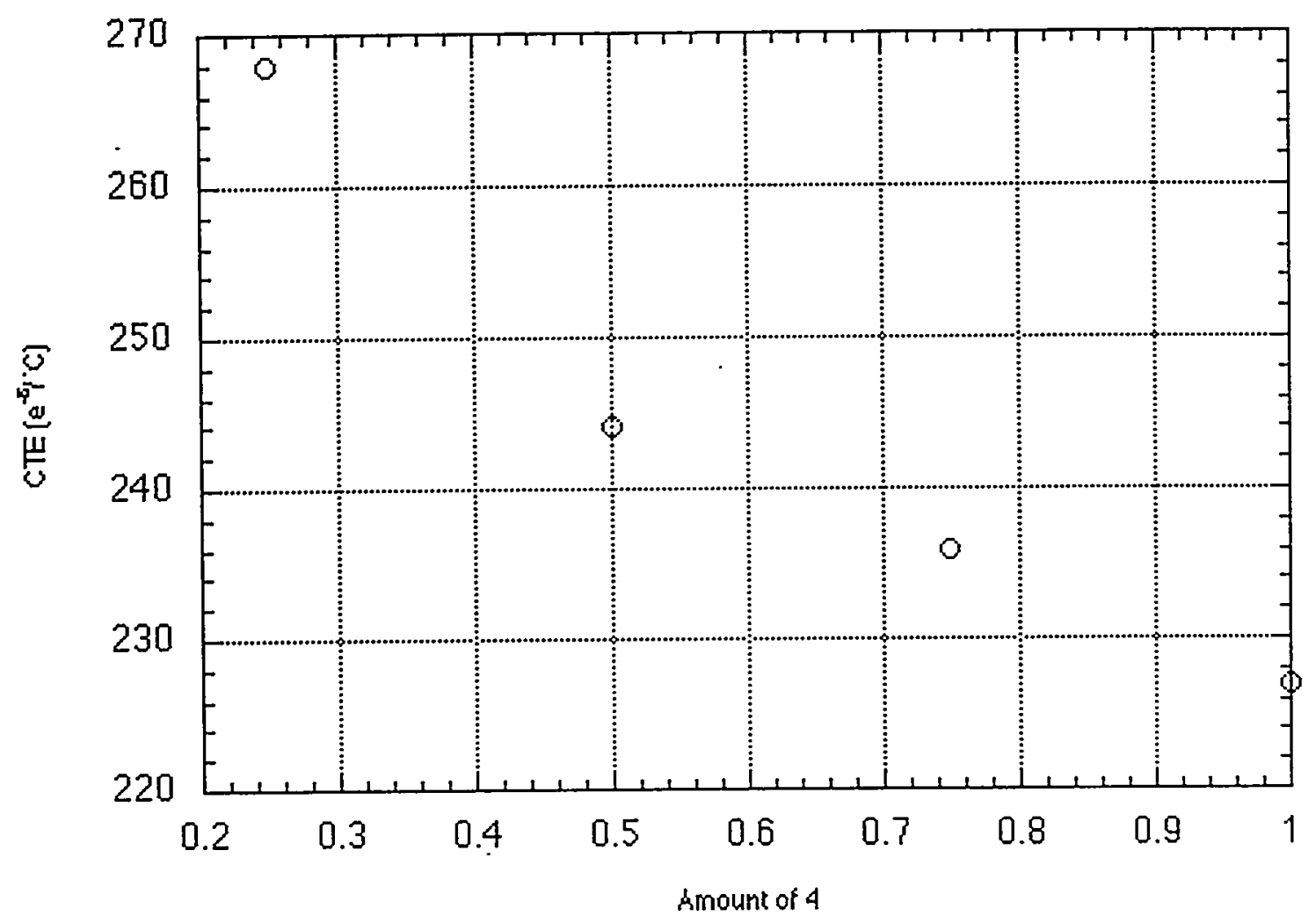

Acid Catalyzed Ring-Opening Polymerization. During the hydrogenation of the ethylenebridged disilaoxacyclopentene, we discovered that catalytic amounts of formic acid, $\mathrm{HCO}_{2} \mathrm{H}$, were needed for the hydrogenation; the use of acids as hydrogenation acccelerators has been demonstrated. ${ }^{3}$ Thus, we performed the hydrogenation of the phenylene-bridged analog under similar conditions, i.e. in the presence of $\mathrm{HCO}_{2} \mathrm{H}$ (hydrogenation without $\mathrm{HCO}_{2} \mathrm{H}$ is complete within 12 hours). Not only did hydrogenation occur, but also the solution gelled when allowed to react overnight. This was contrary to early reports which stated that disilaoxacyclopentenes do not undergo ROP with Lewis acids [3].

Independent polymerizations of 1, 2, and 3 all confirmed that disilaoxacyclopentanes do in fact undergo acid catalyzed ring-opening polymerization using organic protic acids such as $\mathrm{HCO}_{2} \mathrm{H}$ and triflic acid. As expected, polymerization is much more rapid when the stronger triflic acid is used. Photo-acid generators such as $\mathrm{Ph}_{2} \mathrm{I}\left(\mathrm{O}_{3} \mathrm{SCF}_{3}\right)$ and UV9310C (available from GE-Silicones) also ring-open polymerize disilaoxacyclopentanes upon exposure to short-wave ultraviolet light.

Thin Film Applications. Disilaoxacyclopentanes have potential for use as thin films, as they are easily procecssible (they do not shrink or crack during polymerization and do not produce unwanted VOC's). We have been exploring their use in such applications as spray coatings and thin films for membranes. Figure 3 demonstrates some of the early results from these studies, a thin film of the copolymer mixture of $1: 2$ on an alumina substrate. The fluid monomer mixture was in situ polymerized on the substrate over a layer of TBAH, which was 
applied prior to spin coating of the mixture. They display good adhesion on the alumina substrate, no cracking or voids are seen on the films.
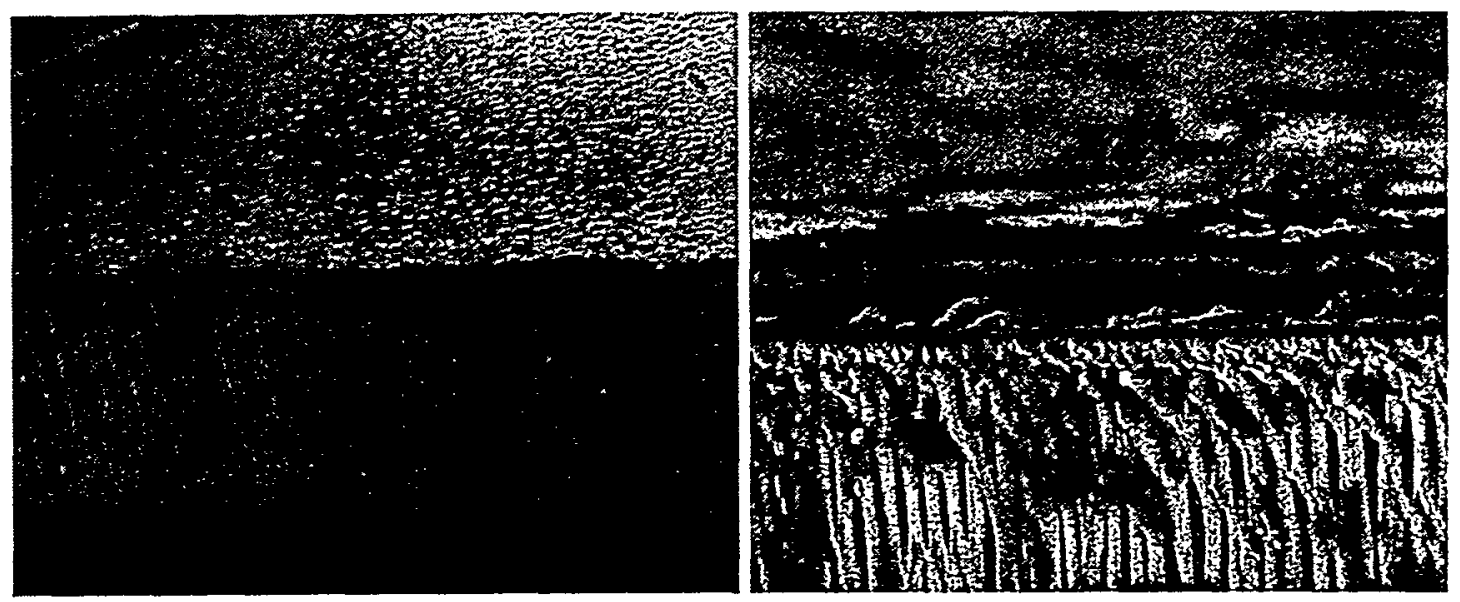

Figure 3. SEM photographs of $1 / 2$ copolymer system on $0.02 \mu M$ alumina disk.

\section{CONCLUSIONS}

We have synthesized novel alkylene-bridged disilaoxacyclopentanes through the same methodology utilized in the synthesis of phenylene-bridged disilaoxacyclopentane, 1 . These precursors can be ring-open polymerized in the same manner as 1, using tetrabutylammonium hydroxide as the catalyst. We have also demonstrated the first acid-catalyzed ring opening polymerization of disilaoxacyclopentanes, using protic acids such as formic acid and triflic acid, as well as photo-acid generators (PAG). The use of PAG's has allowed us to explore these materials for conformal coatings and microlithography, which we are currently exploring, as well as thin films for use in such applications as membranes. As well, the linear relationship between the amount of the crosslinking component and the thermal properties of the final materials allows us to easily engineer the properties to the need of the application.

\section{ACKNOWLEDGEMENT}

We would like to thank Jeff Kawola for his assistance in the thin films and Bonnie McKenzie for SEM work. Sandia is a multiprogram laboratory operated by Sandia Corporation, a Lockheed Martin Company, for the United States Department of Energy under Contract DEAC04-94AL85000.

\section{REFERENCES}

(1) D. A. Loy, K. Rahimian, M. Samara, Angew. Chem. Int. Ed., 38, 555 (1999).

(2) P. N. Rylander, Hydrogenation Methods (Academic Press 1985).

(3) B. Suryanarayan, B. W. Peace, K. G. Mayhan, J. Polym. Sci.; Chem. Ed., 12, 1089 (1974). 